Some government grant was received to assist the Society's work, but by the early years of this century the Society had been financially exhausted by the efforts to maintain the Ben Nevis observatory, which had, unhappily, to be closed in 1904. Negotiations with the Government resulted in 1912 in the granting of an annual sum of $£ 350$ from the Meteorological Office on condition the Society maintained an office in Edinburgh to provide for public service under the guidance of a committee, of which Sir Napier Shaw, director of the Office, was appointed chairman. Financial difficulties after the First World War led in 1920 to the complete taking over by the Meteorological Office of the Society's office and its public responsibilities, and at the same time an official Meteorological Advisory Committee for Scotland was set up with the director of the Office as chairman and a membership of representatives of the Scottish universities, learned societies and government departments.

The purpose of the Society, to establish meteorological work in Scotland on a permanent and comprehensive basis, having been achieved, the Society amalgamated in 1921 with the Royal Meteorological Society, which since 1944 has had as one of its honorary officers a secretary, more recently a vice-president, for Scotland. The balance of the funds was used to found the Royal Meteorological Society's Buchan Prize for meteorological research. Meetings of the Royal Meteorological Society were held in Scotland in 1921 and 1954, and a flourishing Scottish Centre was formed in 1946. Some famous names in meteorology connected with the Scottish Meteorological Society have been mentioned. To them may perhaps be added that of C. K. M. Douglas, who joined the Society in 1916 and published his first paper, on weather observations from aircraft, in the Journal the same year.

\section{INTERNATIONAL REVIEW OF EDUCATION}

$\mathrm{T}$

HE problems of educational theory and practice, of educational psychology and sociology, of education in home, school and society, have become, more than ever before, matters of international concern. National educational systems and national educational ideas can no longer safely be developed without contact with educational thought and action elsewhere in the world. The maintenance of cultural life has ceased to be something to be guided by ideals purely national in scope.

For these reasons a new educational journal designed to provide an international forum and to promote international exchange of information does not require extended justification. The International Review of Education has been launched on behalf of the Unesco Institute of Education, Hamburg, and edited by Karl W. Bigelow of New York, Roger Gal of Paris, M. J. Langeveld of Utrecht, Walther Merck of Hamburg and Friedrich Schneider of Munich. Editorial consultants have been appointed in various countries throughout tine world and include such well-known names as Prof. C. H. Dobinson, Prof. M. U. C. Jeffreys and Prof. F. J. Schonell.

One aim of the new journal will be to inform readers as to educational theory and practice in various countries. Another-and perhaps the more important-will be to explore the extent to which such ideas and activities have elements of validity that transcend national boundaries. Such exploration will, of course, require continuing discussion and debate.

In pursuance of its aims the Review hopes to develop an ever-strengthening chain of contacts with educational research and training centres throughout the world. Systematic attention will also be paid to international educational conferences and congresses, as well as those of more limited scope which possess special international interest. From the torrent of educational publications appearing everywhere it is the intention to select those of outstanding extranational significance for critical examination.

The first four numbers of the journal have now appeared, and each contains articles in English, French and German; articles in one of these languages contain useful summaries in the other two. Besides articles by leading English educationists, the first volume of the journal contains a valuable account of the reforms in the French educational system since the War; a bird's-eye view of education in India; a description of educational reform and its problems in post-war Japan; two articles of different points of view on nationalism and internationalism; a survey of political education in France, Great Britain, Germany and the United States; a penetrating inquiry into the state of American education and its relation to politics; a comparison between "le français élémentaire" and basic English which suggests the latter may be too basic ; and an interesting account of the way vocational training in Germany has been humanized.

\section{SOURCES OF ANIMAL BEHAVIOUR}

TN his inaugural address, delivered on May 5, 1955, at University College, London, and recently published*, Prof. G. P. Wells has drawn forcible attention to the importance of spontaneous rhythms in animal behaviour. His analytical studies of the lugworm Arenicola over the past twenty years have shown how little the normal behaviour of this worm seems to depend on the reflexes of a passive animal and how much depends on inherent rhythmic activity. Burrowing, feeding, defæcation and respiration are controlled by 'physiological clocks'. 'There is rhythmic activity originating from the osophagus, and this itself recurs in outbursts controlled by rhythms of a higher order.

In any species there are many patterns of these rhythms, and the animal may pass abruptly from one pattern to another. These patterns vary with the species; and the different patterns of rhythms are recognizably characteristic of each species, quite as much as are the anatomical characters by which they are distinguished systematically.

To illustrate the generality of rhythmic patterns, Prof. Wells shows that, just as in his Arenicola, much jecent work on the behaviour of birds suggests that this is governed by a variety of spontaneous rhythms - that is, regular activity not directly related to environmental stimuli. Rhythmic outbursts of song, feeding and reproductive cycles of behaviour recall the spontaneous rhythms of the worms. It is true that bird behaviour differs from worm behaviour in

* The Sources of Animal Behaviour. (An Inaugural Lecture delivered at University College, London, 5 May, 1955.) By Prof. G. P. Wells. 
its much greater complexity and in the much greater indirect influence of external stimuli upon the rhythms and their patterns. But the fact remains that much that is most characteristic of the behaviour of both worms and birds depends on highly individual patterns of rhythmic activity apparently of internal origin.

The address is stimulating and leads one to many questions. What are these 'clocks' that control rhythmic behaviour? When we consider rhythmic contractility, on one hand, and reproductive cycles, on the other, it is clear that the clocks work on very varied principles. The one common feature is the rhythmic activity of the system whatever its grade of organization. Possibly it is a general character that they are systems in relaxation oscillation. Living organisms are dynamic, and it does not follow that they will naturally tend towards a constant steady state. Indeed, in many cases such steadiness is only achieved by the evolution of elaborate controls-as the proprioceptive machinery of limbs. Systems in relaxation oscillation may arise at meny different levels of organization. Once they are there, they may inevitably be built into the behaviour of the organism through the operation of natural selection.
C. F. A. Pantin

\section{USE OF LOGARITHMIC NOTATION IN SCIENCE AND ENGINEERING}

\section{By Prof. S. DEVONS, F.R.S. University of Manchester}

$\mathrm{F}^{\mathrm{o}}$ OR the past ten or twelve years I have been using, and encouraging colleagues and students to adopt, a logarithmic system of notation, in place of the conventional arithmetical one, as the normal one in which to express physical magnitudes and relations. Suggestions that logarithmic scales and units be used more widely have been made by numerous writers, and such systems have obvious advantages. The experience gained in the use of $a_{0}$ general system of this sort confirms that the advantages are substantial, perhaps more than is generally appreciated, and that they definitely outweigh its drawbacks and are sufficient to justify its more widespread use.

A large proportion of statements in physical science are in the form : the quantity $X$, as measured (calculated), is $n$ times a specified unit. The number $n$ is not normally integral or exact. It is not arrived at by counting but by computation from primary physical measurements (empirical quantities), and in this process of computation multiplication plays a dominant part. One can see that this is the case by inspecting a typical table in a compilation of physical data, such as fundamental constants ${ }^{1}$, electrical resistivitios of metals ${ }^{2}$, wave-lengths of X-ray lines ${ }^{3}$ or abundances of isotopes ${ }^{4}$. One will find, normally, that the numbers are spread roughly uniformly over a limited logarithmic scale: for example, about 30 per cent of the entries will have the first significant figure 1 , whereas only 5 per cent will begin with 9 . (Even when the primary quantities are not 'logarith. mic', the quantities derived after a few multiplicative steps soon tend to be so.)

The fact that most, although not all, of the quantities used in physical expressions and calculations are of this 'logarithmic' sort suggests that the normal notation to be used in expressing them, and numerical relations between them, should also be logarithmic, with some convenient unit of relative magnitude. A very convenient unit that has long been used in several branches of physics and engineering to denote a ratio of powers is the decibel $\left(10^{1 / 10}\right.$, or approximately a factor $1 \cdot 2$ ), and many proposals have been made to adopt it (either with the same or a new name) for wider use. For the quite general use proposed in this article, a simpler and more distinct name and notation is called for. I have used the term 'jot' for the unit, and I have found the notation $x=$ (unit $\pm x y z . a b)$ jot, with the word 'jot' normally omitted, to be simple and unambiguous. It readily permits the simultaneous use of logarithmic and normal notation. Thus, for example, electron charge $=($ e.s.u. $-93 \cdot 2)$, velocity of light $(\mathrm{cm} . /$ sec. +104.8$)$, to an implied accuracy of \pm 0.05 jot (or about 1 per cent). No confusion arises in addition, subtraction, etc.; for example, (c.g.s. + 82.1) + (c.g.s. $+86 \cdot 2$ ). A notation such as this which emphasizes the unit has considerable pedagogic value. Some other advantages of the logarithmic notation are as follows.

Simplicity of calculation. Just as so many of the physical quantities one deals with are 'logarithmic', so, naturally, the arithmetical manipulations in which they are involved are predominantly multiplicative (including roots, powers, reciprocals). These manipulations become, obviously, greatly simplified and far less liable to error if one starts, works and finishes with the quantities expressed in logarithmic notation. Of course, addition and subtraction become more complicated, but since these operations normally involve quantities of the same order of magnitude, whereas multiplication often involves many orders of magnitude, it is advantageous to have the notation suited to the more frequent and important operation.

Economy of notation. As previously indicated, ordinary arithmetical notation does not use all the digits equally when dealing with usual physical magnitudes. Less digits are required, on the average, to indicate a specified accuracy on the logarithmic scale. This, coupled with the simpler notation, makes quantities expressed logarithmically easier to write, remember, and particularly to manipulate mentally. Compare, for example, $m=1.67 \times 10^{-24} \mathrm{gm}$. with $m=$ (gm. $-237 \cdot 8$ ), which has three less digits, and all the digits are on a similar footing.

Another feature of the logarithmic system is the possibility of 'normalizing' the scale of measurement so that a high accuracy can be expressed with few digits. For example, the specific gravity of a liquid might be expressed as (unity $+0 \cdot 2$ ), with an accuracy of 1 per cent, whereas normally this accuracy would require three digits.

Simplification of units. An expression such as $a_{0}=5.292 \times 10^{-0}$ centimetres (Bohr radius) is clearly both inconsistent and uneconomical in its notation. First, we have a mixture of logarithmic and linear notations: the digits themselves are 